\title{
Exploring relationships between mechanical properties of marl core samples by a coupling of mutual information and predictive ensemble model
}

\author{
S. Salehin ${ }^{1} \cdot$ E. Hadavandi ${ }^{2} \cdot$ S. Chehreh Chelgani ${ }^{3}$ (D)
}

Received: 10 July 2019 / Accepted: 21 October 2019 / Published online: 2 November 2019

(c) The Author(s) 2019

\begin{abstract}
Inappropriate evaluation of uniaxial compression indexes ( $E$ and UCS) of rocks in high seismic intensity areas such as dam regions can lead to underestimation of the load, and possible settlement of the structure. Indirect assessments of these rock mechanical indexes based on non-destructive experiments and by using intelligent models is a well-accepted method to overcome associated limitations with laboratory tests of $E$ and UCS. This study introduces the mutual information (MI) method as a unique system for variable importance measurement (VIM) and feature selection. Conducting MI-VIM assessments between various analyses of marl core samples (depth, density, ultrasonic tests $\left(\nu_{\mathrm{d}}, \mathrm{V}_{\mathrm{p}}\right.$ and $\left.V_{\mathrm{s}}\right)$, Brazilian test $(\sigma \mathrm{t})$ ), triaxial compression test ( $C$ and and $\phi$ ) and point load test $\left(I_{\mathrm{s}}(50)\right)$ indicated that $V_{\mathrm{s}}$ and $\sigma \mathrm{t}$ had the highest importance for $E$ and UCS prediction. adaptive boosting-neural network ensemble (Adaboost-NNE) was used for the prediction of $E$ and UCS. Testing of the generated Adaboost-NNE indicated that this model could accurately predict UCS and $E$ with correlations of determinations 0.98 and 0.92 , respectively. These results showed that VIM of MI coupled with Adaboost-NNE could develop a robust model that can be used for the prediction and modeling of other indexes of rocks.
\end{abstract}

Keywords Marls $\cdot$ Dam $\cdot$ Variable importance $\cdot$ Maintenance $\cdot$ Brazilian test $\cdot$ Mutual information

\section{Introduction}

The study of geotechnical and mechanical properties of rocks would be critical keys for the construction, control, and maintenance of high seismic intensity regions such as dam areas. Seydoon dam (Khoozestan Province, southwest of Iran) has been constructed over a series of marls, shale and sandstones. Among these rocks, marls are particularly important due to their specific properties. Marls are composed of clay and carbonate minerals in different proportions and their characters mainly depend on the

\section{S. Chehreh Chelgani}

Sos4552@gmail.com

1 Rock Mechanics Laboratory, University of Tehran, Tehran, Iran

2 Department of Industrial Engineering, Birjand University of Technology, Birjand, Iran

3 Minerals and Metallurgical Engineering, Department of Civil, Environmental and Natural Resources Engineering, Luleå University of Technology, 97187 Luleå, Sweden type and percentage of carbonate and clay minerals (Bellair and Pomerol 1980; El Amrani et al. 1998). It is well accepted that the force load in dam areas has a large effect on the mechanical properties of rocks, such as elasticity and strength (Abrams 1917; Watstein 1953; Malvar and Ross 1998; Yan and Lin 2006). Uniaxial compressive strength (UCS) and Young's modulus $(E)$ can be used to determine the durability of rocks against weathering agents and their fabrics. UCS and $E$ are also can be used to determine their deformation and bearing capacity (Dehghan et al. 2010; Matin et al. 2017). Therefore, the determination of UCS and $E$ for marls from the ground of the dam can play an essential role in understanding their mechanical properties and help to do appropriate maintenance for the site.

American Standards for Testing Materials (ASTM) and International Society for Rock Mechanics (ISRM) have been introduced as standard procedures for the determination of UCS and $E$. However, direct determinations of these indexes based on ASTM and ISRM approaches in the laboratory have few drawbacks (complex sample preparation, expensive and time consuming process) (Sousa 2014; Jamshidi et al. 2016a, b; Armaghani et al. 2016a, b). For solving limitations 
associated with laboratory tests, various investigations were performed for the indirect determination of UCS and $E$, based on non-destructive index experiments. In those studies, mineral properties (composition, porosity and density), ultrasonic tests [P-wave velocity $\left(V_{\mathrm{p}}\right)$ and $\mathrm{S}$-wave velocity
$\left.\left(V_{\mathrm{p}}\right)\right]$ and other standard indexes were used to predict UCS and $\mathrm{E}$ by regression or other intelligent computing methods [i.e., artificial neural networks (ANNs) or the adaptive neuro-fuzzy inference system (ANFIS)] (Demirdag et al. 2010; Ersoy and Kanik 2012; Armaghani et al. 2016a, b).

Table 1 Various experiments on core of marls and their representative UCS and E

\begin{tabular}{|c|c|c|c|c|c|c|c|c|c|c|}
\hline \multirow[t]{2}{*}{ Depth (m) } & \multirow{2}{*}{$\begin{array}{l}\text { Index properties } \\
\text { Density }\left(\mathrm{kN} / \mathrm{cm}^{3}\right)\end{array}$} & \multirow{2}{*}{$\begin{array}{l}\text { Point load test } \\
I_{\mathrm{s}(50)}\end{array}$} & \multirow{2}{*}{$\begin{array}{l}\text { Brazilian test } \\
\sigma \mathrm{t}(\mathrm{MPa})\end{array}$} & \multicolumn{2}{|c|}{$\begin{array}{l}\text { Uniaxial compression } \\
\text { test }\end{array}$} & \multicolumn{3}{|c|}{ Ultrasonic test } & \multicolumn{2}{|c|}{ Triaxial test } \\
\hline & & & & UCS (MPa) & $\overline{E_{\mathrm{d}}(\mathrm{GPa})}$ & $\overline{V_{\mathrm{P}}(\mathrm{m} / \mathrm{s})}$ & $V_{\mathrm{S}}(\mathrm{m} / \mathrm{s})$ & $\nu_{\mathrm{d}}$ & $c(\mathrm{MPa})$ & $\phi\left(^{\circ}\right)$ \\
\hline $12.3-12.7$ & 2.4 & 0.4 & 1.02 & 1.91 & 0.84 & 2204 & 1155 & 0.31 & 1.389 & 31.021 \\
\hline $12.7-13.2$ & 2.45 & 0.18 & 1.75 & 3.98 & 1.1 & 2680 & 1287 & 0.35 & 0.623 & 49.865 \\
\hline $13.6-14.2$ & 2.5 & 0.21 & 2.65 & 7.95 & 0.95 & 2113 & 1237 & 0.24 & 1.513 & 28.448 \\
\hline $15.1-15.4$ & 2.43 & 0.05 & 0.78 & 6.47 & 1.2 & 2412 & 1414 & 0.24 & 1.687 & 29.784 \\
\hline $16.7-17.35$ & 2.36 & 0.06 & 0.96 & 0.27 & 0.97 & 2213 & 1281 & 0.25 & 1.235 & 30.382 \\
\hline $17.35-17.75$ & 2.41 & 0.05 & 1.23 & 0.31 & 1.21 & 2991 & 1351 & 0.37 & 1.408 & 34.678 \\
\hline $18.7-19.1$ & 2.41 & 2.12 & 2.24 & 3.16 & 1.02 & 2669 & 1244 & 0.36 & 0 & 38.949 \\
\hline $19.1-19.5$ & 2.42 & 0.08 & 0.82 & 5.57 & 1.12 & 2298 & 1380 & 0.22 & 0.485 & 49.882 \\
\hline $21.75-22.25$ & 2.54 & 3.57 & 1.12 & 5.29 & 1.35 & 3036 & 1395 & 0.366 & 0.057 & 38.807 \\
\hline $23-23.27$ & 2.51 & 4.23 & 1.6 & 5.29 & 1.11 & 2187 & 1369 & 0.18 & 1.721 & 24.387 \\
\hline $23.27-23.6$ & 2.48 & 2.75 & 3.39 & 10.79 & 1.52 & 2621 & 1592 & 0.21 & 0.733 & 49.874 \\
\hline $23.72-24.09$ & 2.47 & 0.08 & 0.94 & 4.81 & 1.19 & 2610 & 1351 & 0.32 & 1.15 & 33.654 \\
\hline $25.35-25.75$ & 2.43 & 1.87 & 0.48 & 2.73 & 0.97 & 3672 & 1174 & 0.44 & 1.324 & 37.824 \\
\hline $28.3-28.65$ & 2.43 & 3.81 & 2.62 & 4.03 & 1.15 & 2741 & 1322 & 0.35 & 0.985 & 39.689 \\
\hline $29.25-29.49$ & 2.5 & 7.92 & 2.5 & 16.29 & 2.02 & 3188 & 1781 & 0.27 & 1.213 & 53.214 \\
\hline $29.84-30.11$ & 2.59 & 8.74 & 9.95 & 38.57 & 3.41 & 3700 & 2416 & 0.13 & 0.213 & 54.125 \\
\hline $30.5-30.8$ & 2.52 & 0.51 & 0.67 & 1.47 & 1.05 & 2848 & 1226 & 0.39 & 1.101 & 41.518 \\
\hline $30.8-31.1$ & 2.48 & 7.1 & 4.65 & 10.79 & 1.8 & 3088 & 1675 & 0.29 & 1.146 & 38.452 \\
\hline $32.65-32.9$ & 2.53 & 8.35 & 10.4 & 36.99 & 3.91 & 4043 & 2587 & 0.15 & 0.134 & 60.391 \\
\hline $32.85-33.35$ & 2.5 & 8.76 & 6.84 & 20.9 & 2.45 & 3607 & 1947 & 0.294 & 1.11 & 38.257 \\
\hline $33.55-33.85$ & 2.51 & 8.79 & 8.86 & 38.34 & 3.98 & 4123 & 2607 & 0.17 & 0.068 & 60.366 \\
\hline $35-35.4$ & 2.52 & 1.98 & 3.54 & 15.67 & 1.83 & 2950 & 1708 & 0.248 & 1.567 & 49.061 \\
\hline $39.6-40$ & 2.47 & 0.12 & 2.4 & 5.48 & 1.28 & 3002 & 1377 & 0.367 & 0.847 & 42.212 \\
\hline $40-40.35$ & 2.58 & 7.96 & 3.02 & 17.4 & 1.71 & 2840 & 1623 & 0.26 & 0.43 & 46.243 \\
\hline $40.52-41$ & 2.46 & 6.9 & 5.44 & 24.12 & 2.8 & 3567 & 2175 & 0.2 & 0.062 & 58.078 \\
\hline $46.15-46.38$ & 2.55 & 5.35 & 1.42 & 6.42 & 1.31 & 2605 & 1412 & 0.29 & 1.014 & 38.315 \\
\hline $46.38-46.88$ & 2.62 & 1.44 & 5.64 & 16.6 & 2.06 & 3000 & 1793 & 0.22 & 0.435 & 53.143 \\
\hline $50-50.2$ & 2.54 & 8.23 & 7.66 & 30.56 & 2.93 & 3521 & 2216 & 0.17 & 0.035 & 60.032 \\
\hline $51.55-52.15$ & 2.47 & 0.13 & 0.79 & 3.83 & 1.19 & 3128 & 1315 & 0.39 & 1.253 & 30.443 \\
\hline $52.15-53.05$ & 2.54 & 7.2 & 4.12 & 12.191 & 1.79 & 2825 & 1705 & 0.214 & 0 & 39.318 \\
\hline $55.5-55.77$ & 2.5 & 0.57 & 1.96 & 4.15 & 1.19 & 2746 & 1327 & 0.35 & 1.374 & 29.547 \\
\hline $55.9-56.4$ & 0.77 & 0.62 & 2.48 & 11.95 & 0.52 & 3030 & 1619 & 0.3 & 0.834 & 47.525 \\
\hline $56.2-56.5$ & 2.26 & 0.92 & 1.32 & 2.35 & 0.97 & 2680 & 1259 & 0.36 & 1.163 & 33.471 \\
\hline $56.4-56.8$ & 1.25 & 5.96 & 3.84 & 7.96 & 0.72 & 2885 & 1470 & 0.32 & 0.601 & 49.984 \\
\hline $56.8-57.15$ & 0.53 & 1.74 & 1.81 & 14.53 & 0.4 & 3124 & 1716 & 0.28 & 0.258 & 54.023 \\
\hline $57.7-57.92$ & 2.46 & 7.58 & 6.53 & 28.09 & 2.91 & 3618 & 2223 & 0.2 & 0.638 & 43.601 \\
\hline $66.3-66.65$ & 0.58 & 0.82 & 2.06 & 11.44 & 0.38 & 3011 & 1600 & 0.3 & 0.285 & 52.225 \\
\hline $67.3-67.68$ & 2.38 & 0.76 & 1.48 & 7.98 & 1.36 & 2886 & 1470 & 0.32 & 1.104 & 34.241 \\
\hline $69.6-70.18$ & 0.45 & 1.17 & 3.1 & 4.64 & 0.22 & 2764 & 1345 & 0.34 & 0.993 & 40.276 \\
\hline
\end{tabular}


Fig. 1 Dependency measurement among input variables by MI for the prediction of UCS and $E$
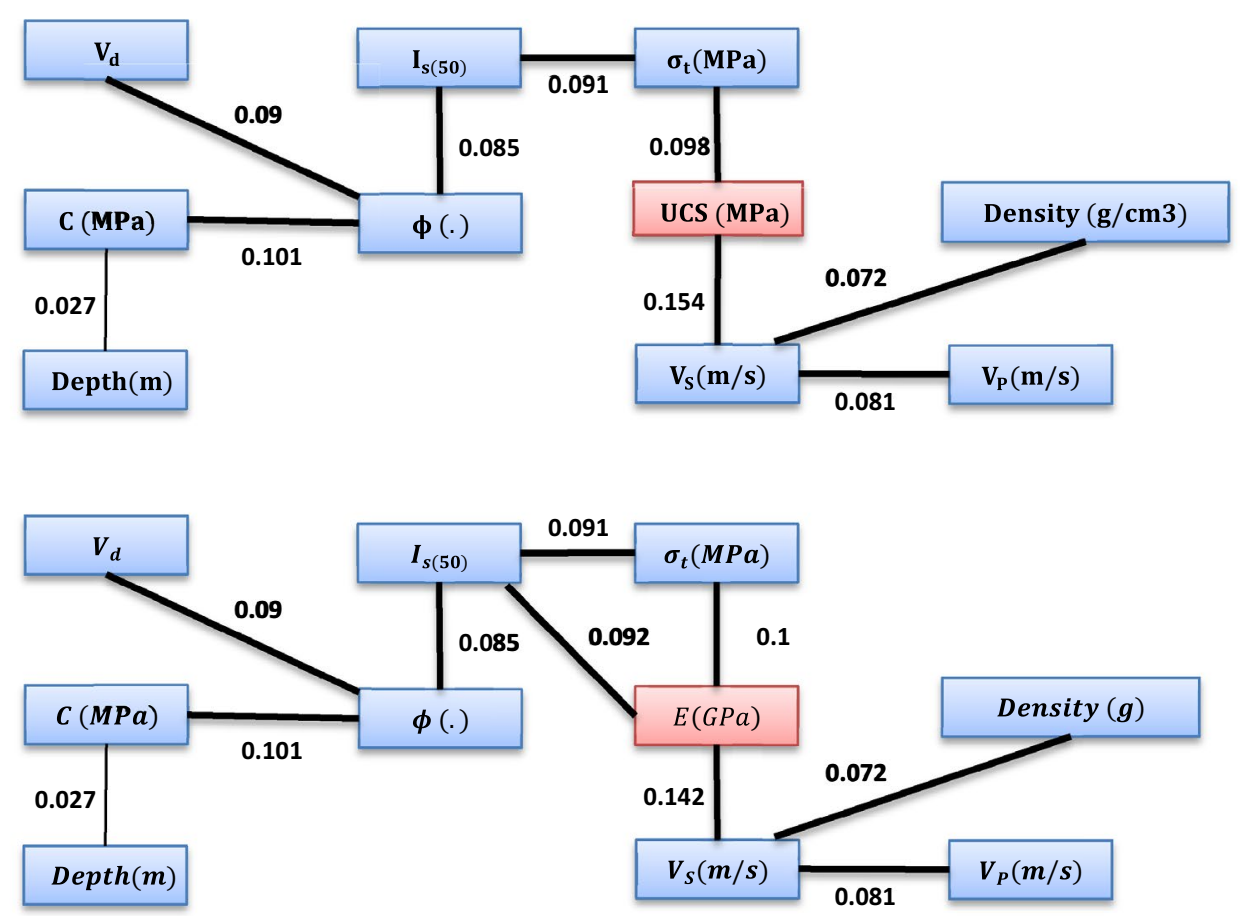

For generating a robust predictive model, it is essential to build a highly accurate system based on the most relevant parameters (inputs). Development of a model which can explore inter-correlations through various variables, detect and select the most effective ones [variable importance measurement (VIM)], and use them as inputs of a precise predictive model has several advantages: as irrelevant variables make noises in modeling, by VIM redundant variables can be removed (save time and reduce cost of analyses) and outliers (influential points) identified (Chehreh Chelgani et al. 2016a, b; Matin and Chelgani 2016; Matin et al. 2016; Shahbazi et al. 2017).

Mutual information (MI) is an intelligent computer method which can explore both the linear and nonlinear relationship between wide ranges of inputs and rank them based on their influences. In other words, MI provides a decision-making system that can be used to select the most effective inputs (variables which can represent the influence of other ones) and reduce the noises for the development of a model (Chelgani et al. 2018). In a predictive modeling problem, various researches indicated that combination of intelligent predictor models and development of an ensemble of predictors (experts) can construct an accurate model to deal with complicated problems (Masoudnia et al. 2012; Hadavandi et al. 2015, 2016). One of the popular ensemble methods is the neural network ensemble (NNE) (Hansen and Salamon 1990) and an efficient approach for creating an NNE model is Adaptive Boosting (Adaboost) that can adaptively improve the probability of sampling cases for accurate training experts for the NNE model. This approach can develop a model by using a wide distribution of inputs and reduce the prediction errors by considering the information of previous experts (Hansen and Salamon 1990; Freund and Schapire 1996; Solomatine and Shrestha 2004; Masoudnia et al. 2012; Tian et al. 2012; Zhai et al. 2012). Although the last decade has witnessed increasing applications of MI and Adaboost-NNE models, they have not yet been used in the exploration and prediction of earth science sectors. This work explores the relationships between the mechanical properties of marls (from the cores of Seydoon dam) to predict UCS and $E$ based on various analyses (depth, density, ultrasonic tests, Brazilian test, point load test, etc.). The interpretation of variables was evaluated by using MI and Adaboost-NNE predictive models. The results of this investigation would be useful for the maintenance of the dam and could introduce a unique model for the prediction of other rock and geomechanical indexes.

\section{Materials and methods}

\section{Database}

Thirty-nine core marl samples were collected from the Sydoom dam area by drilling exploration boreholes to different depths during geotechnical studies. The density of samples was determined by the weighting of cores. All sample analyses were based on ISRM and ASTM procedures. Core marls were highly weathered and weak against water and cutting blade; therefore, a high-speed thin cutting blade was 
used for sample preparation. Dynamic Poisson ratio $\left(\nu_{\mathrm{d}}\right)$, $\mathrm{S}$-wave $\left(V_{\mathrm{s}}\right)$ and $\mathrm{P}$-wave $\left(V_{\mathrm{p}}\right)$ velocities were measured by 200 and $1000 \mathrm{kHz}$ ultrasonic transducers through core samples. Brazilian test $\sigma \mathrm{t}(\mathrm{MPa})$ was performed by using a 15 ton jack and a pump to generate forces to a cylindrical specimen between Brazilian frames. Point load test $\left(I_{\mathrm{S}}(50)\right)$ core sample was subjected to a comprehensive load between two conical platens and, as a result of tension, the broke point was recorded. UCS and triaxial compression test [cohesion of rock material $(C(\mathrm{MPa}))$ and friction angle of rock material $\left(\phi\left(^{\circ}\right)\right)$ ] of samples were performed by an MTS machine. These tests were done using different confining pressures (1-6 MPa). The results of various experiments and their representative UCS and $\mathrm{E}$ are reported in Table 1.

\section{Mutual information}

Mutual information (MI) as a powerful VIM tool can quantify the inter-dependency between random variables. In other words, MI is the amount of shared information between model inputs. The MI $(0 \ll I(X ; Y) \ll 1)$ between two variables $(X$ and $Y$ ) is defined based on the joint probability distribution $p(x, y)$ and the product distribution $p(x) p(y)$ :

$$
I(X ; Y)=E_{p(x, y)}\left[\log \frac{p(x, y)}{p(x) p(y)}\right]=\sum_{x \int X} \sum_{y \int Y} p(x, y) \log \frac{p(x, y)}{p(x) p(y)},
$$

where $E_{\mathrm{p}}$ is the mathematical expectation. MI can reduce the prediction error by the maximization scheme between input variables and targets. In other words, MI can consider the information of more than single input to predict an output. This system detects the most relative variables, ranked them based on VIM and feed them to the predictive model. Variable selection by MI reduces learning algorithm time, increases the size of the search space and prevents overfitting in the predictive model
(Kerroum et al. 2010; Lee and Kim 2013; Han et al. 2015; Hansen and Salamon 1990; Freund and Schapire 1996; Solomatine and Shrestha 2004; Masoudnia et al. 2012; Tian et al. 2012; Zhai et al. 2012).

\section{Adaptive boosting}

One approach for modeling complicated relationships is generating an ensemble system by combining the single prediction models (based on components) and exploiting the different local behavior of these base models to improve the performance of the overall prediction model (Masoudnia et al. 2012). The neural network ensemble (NNE) is a popular ensemble model that is developed based on a combination of neural network experts (Masoudnia et al. 2012; Tian et al. 2012; Zhai et al. 2012). The sequential manipulating of instances to train an individual neural network is one of the typical methods for the construction of NNEs that is called boosting method (Freund and Schapire 1996). For the last two decades, boosting as one of the most powerful ensemble methods was generated with a high learning capability. Adaptive boosting (Adaboost) changes the distribution of training set based on the performance of the previous NN components which is added in an ensemble model (Adaboost-NNE) (Tian et al. 2012; Zhai et al. 2012). Adaboost-NNE adaptively increases the probability of instances, which have higher prediction errors, by the previous components. The main idea in an Adaboost-NNE model is filtering out examples with the relative prediction error higher than the pre-set threshold value, and then following the Adaboost procedure (Hansen and Salamon 1990; Solomatine and Shrestha 2004). In this study, for prediction of rock mechanic indexes, an Adaboost-NNE model was developed in $\mathrm{T}$ iterations ( $T$ is the number of multi-layered perceptron neural network experts in the ensemble model). The training model is presented in algorithm 1 : 


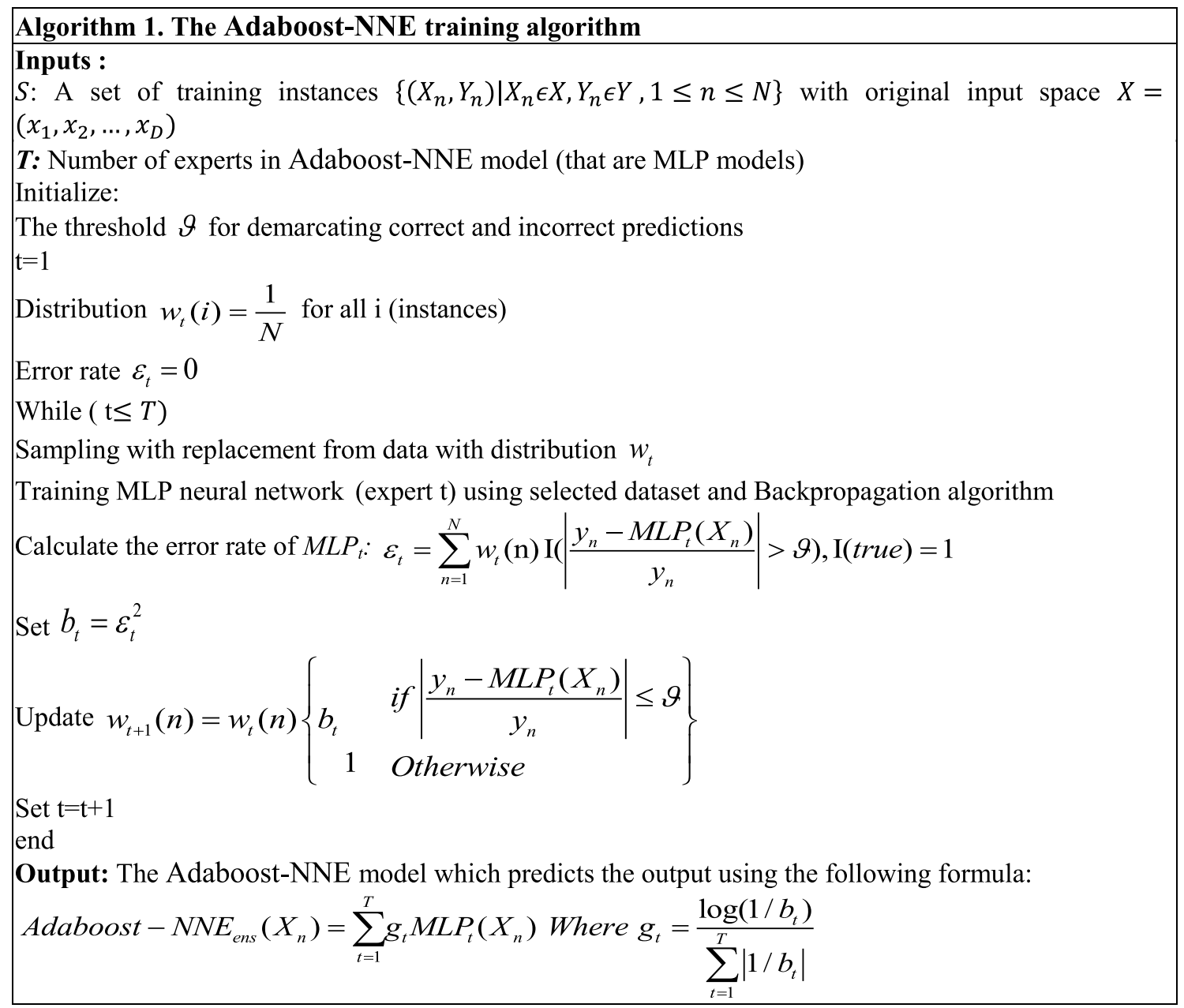

\section{Results and discussions}

\section{Variable selection}

For making a robust system, before generating Adaboost-NNE model for the estimation of UCS and E, VIMs by MI (MI-VIM) is applied through all measured variables $\left(\nu_{\mathrm{d}}, V_{\mathrm{p}}, V_{\mathrm{s}}, I_{\mathrm{s}}(50), \sigma \mathrm{t}\right.$, depth, density, $C$ and $\left.\phi\right)$ to evaluate their importance for the prediction, and as a result select the most effective inputs. MI-VIM results (Fig. 1) indicated that there are complicated interactions among variables, although $\sigma \mathrm{t}$ and $V_{\mathrm{s}}$ showed a direct correlation with the outputs. On the other hand, MI ranked variables based on their importance and results illustrated that $V_{\mathrm{s}}$ and $\sigma \mathrm{t}$ have the highest effectiveness for the prediction of UCS and $E$, respectively (Fig. 2). These outcomes demonstrated that $V_{\mathrm{s}}$ and $\sigma \mathrm{t}$ can represent the correlation of other variables for the generation of predictive models and can be selected as input variables. There is a good agreement with these VIMs and theoretical studies where Castagna et al. (1985) and Pickett (1963) indicated that increasing the percentage of porosity would decrease the strength of rock. Therefore, the velocity of sonic waves ( $\mathrm{P}$ or $\mathrm{S}$ ) would be lower during passing through voids; therefore, results of ultrasonic tests potentially could be a good indicator of the mechanical properties of rocks. Moreover, several investigations demonstrated that sonic waves $\left(V_{\mathrm{p}}\right.$ or $\left.V_{\mathrm{s}}\right)$ can be strong predictors of UCS and $E$ (Yasar and Erdogan, 2004a, b). On the other hand, the dependency evaluation of these indexes with Brazilian tensile strength ( $\sigma \mathrm{t})$ (as an independent variable) showed that $\sigma \mathrm{t}$ can be an appropriate predictor for UCS and $E$ modeling (Jamshidi et al. 2016a, b; Fereidooni 2016).

The complex interactions of selected variables with the outputs are illustrated in Fig. 3. Linear correlations (Pearson correlation) between the MI selected variables and outputs (Table 2) indicate that there are significant positive correlations between them. To develop comprehensive Adaboost-NNE models (with 6 MLP experts) for the prediction 
Fig. 2 Variable importance measurements by MI and ranking inputs for the prediction of UCS and $E$
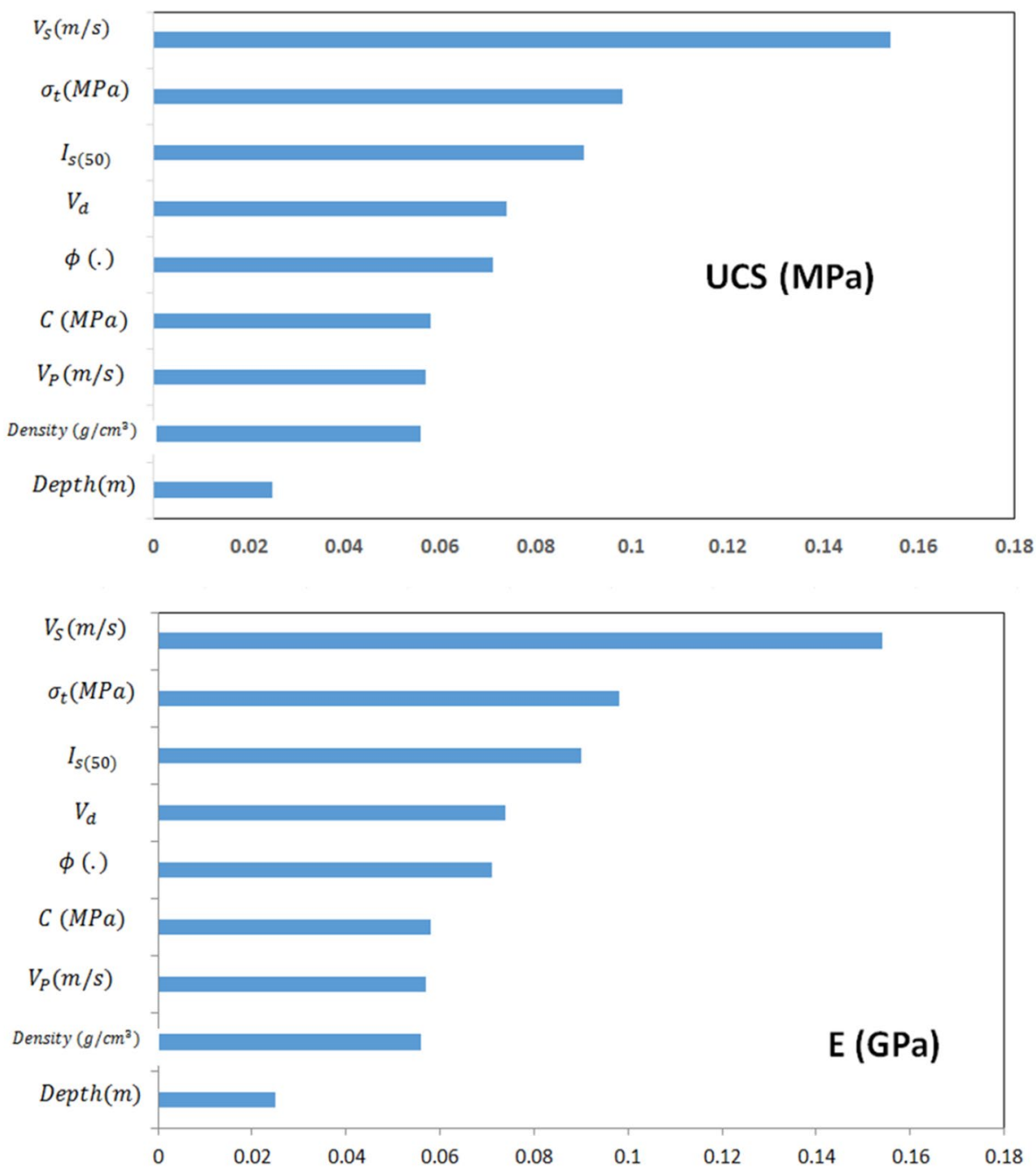

of UCS and $E$ based on MI-VIM selected variables, approximately $75 \%$ of records from the dataset were randomly applied for the training stage and the remaining $25 \%$ of the samples for the testing stage of the models. After training, the model was tested and the results of the testing phase showed that the Adaboost-NNE models could accurately predict the outputs, with the correlation of determination values $\left(R^{2}\right)$ of 0.92 and 0.98 for the $E$ and UCS, respectively.
The differences (Fig. 4) between laboratory measured variables (actual values) and Adaboost-NNE predicated ones showed that models could provide high satisfaction in the prediction of $E$ and UCS. These results indicated the potential of MI coupled with Adaboost-NNE in the prediction of geomechanical indexes, and that these systems can be used for the assessment of other complicated variables in rock mechanics and other related disciplines. 

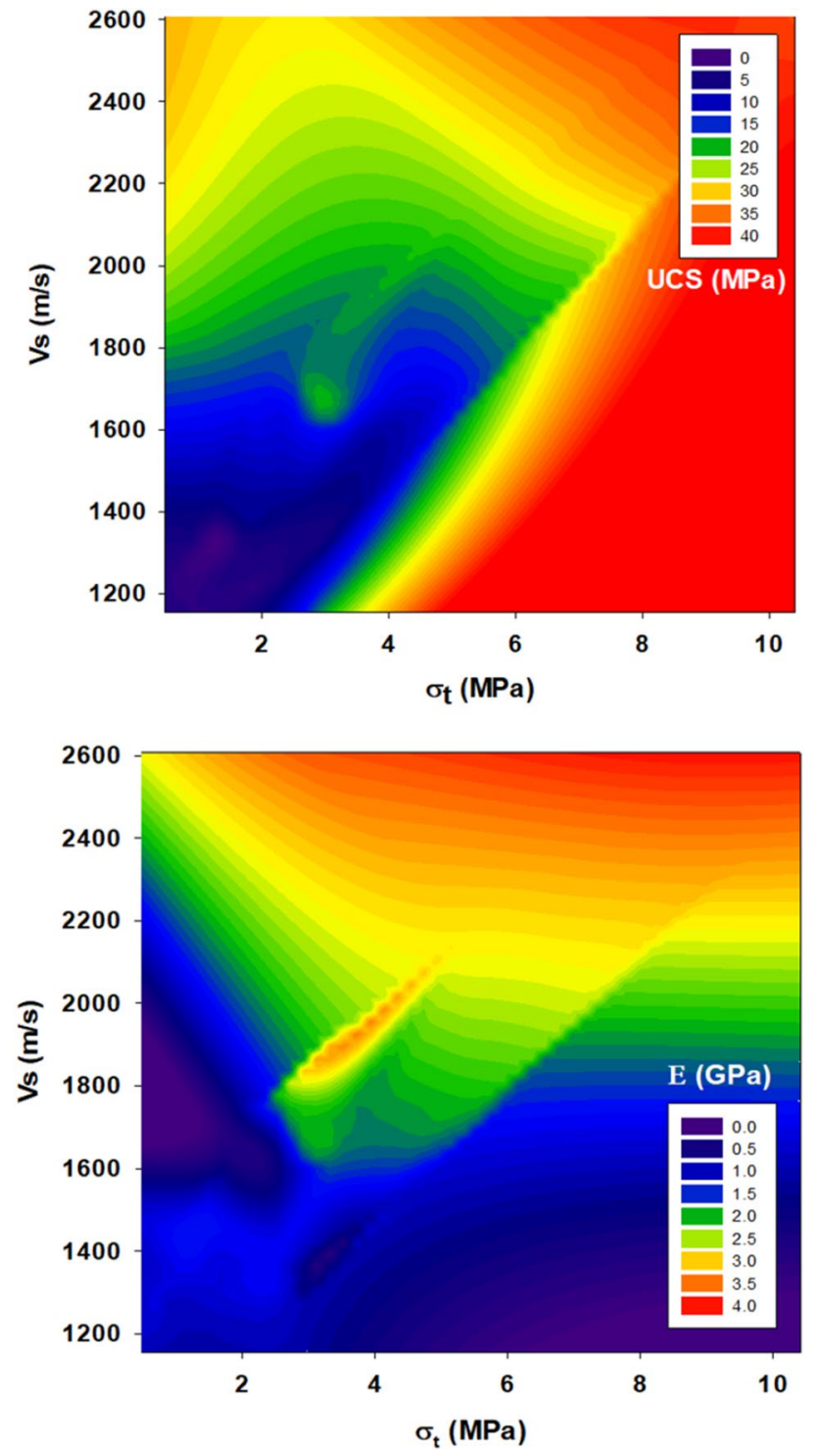

Fig. 3 Topographic relationship between selected variables by MI with UCS and $E$

Table 2 Pearson correlation between VIM selected variables and UCS-E

\section{Conclusion}

Uniaxial compressive strength (UCS) and Young's modulus $(E)$ indexes can play critical roles for the control and maintenance of high seismic intensity regions such as dam areas. This study has introduced a new method [mutual information (MI)] for feature selections through rock properties based on variable importance measurements (VIMs) to predict UCS and $E$ of marls from the Sydoon dam (Iran) by a powerful ensemble method called Adaboost-NNE (adaptive boostingneural network ensemble). MI-VIM can assess the impact of each rock index individually and also in multivariate interactions with other variables. Based on MI-VIM results, the most effective features could be detected and selected to generate an unbiased and broadly applicable Adaboost-NNE model. Various rock mechanic analyses were performed [depth, density, ultrasonic tests $\left(V_{\mathrm{p}}\right.$ and $\left.V_{\mathrm{s}}\right)$, Brazilian test $(\sigma \mathrm{t})$, and point load test], MI-VIM through provided variables indicated that $V_{\mathrm{s}}$ and $\sigma \mathrm{t}$ have the highest importance for the prediction of both UCS and $E$ among other measured parameters. These two variables were selected to generate predictive Adaboost-NNE models. Testing results of the developed models indicated that Adaboost-NNE could predict UCS and $E$ quite accurately with the correlation of determination values of 0.98 and 0.92 , respectively. These results demonstrated that variable selection by MI and prediction by Adaboost-NNE make a robust system which can be used for expanding the knowledge surrounding modeling of rock and geomechanical indexes, and powerful tools for control and maintenance of other embankments.

\begin{tabular}{lll}
\hline Variables & $\sigma \mathrm{t}$ & $V_{\mathrm{s}}$ \\
\hline UCS & 0.93 & 0.98 \\
$E$ & 0.87 & 0.90 \\
\hline
\end{tabular}


Fig. 4 Relationship between predicted and actual value of UCS and $E$, and their differences
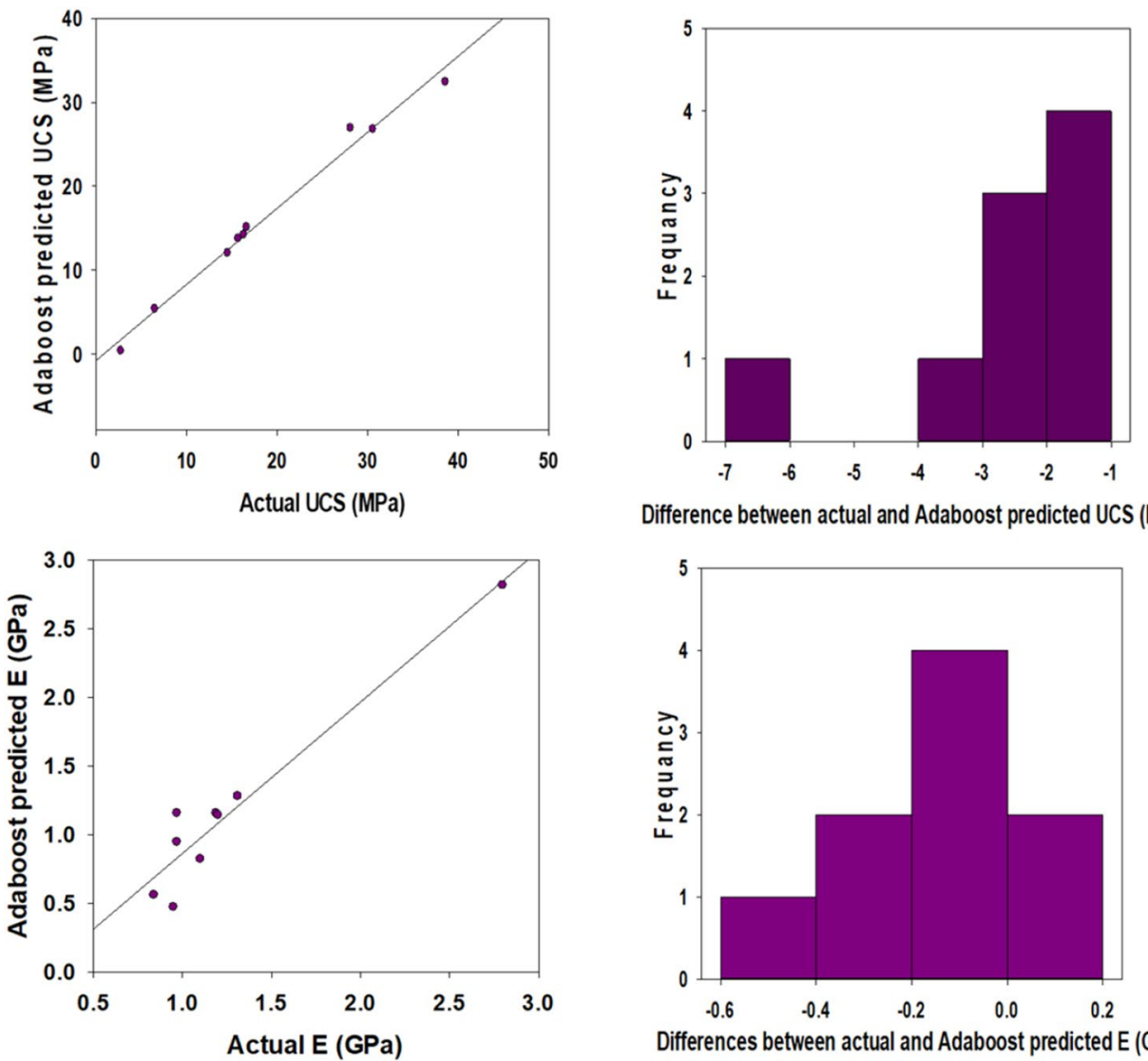

Difference between actual and Adaboost predicted UCS (MPa)

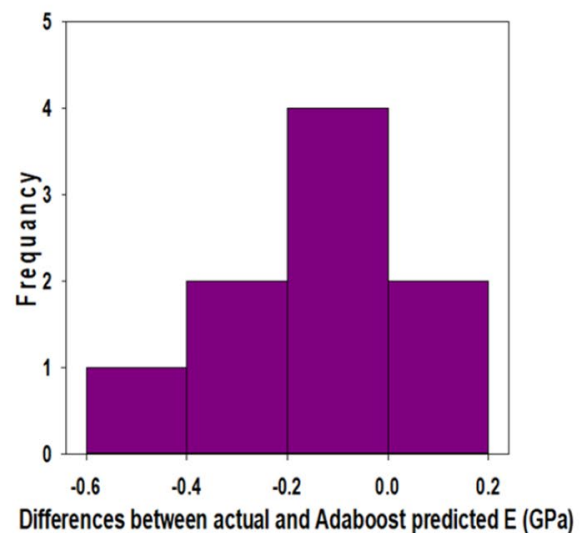

Acknowledgements Open access funding provided by Lulea University of Technology.

Open Access This article is distributed under the terms of the Creative Commons Attribution 4.0 International License (http://creativeco mmons.org/licenses/by/4.0/), which permits unrestricted use, distribution, and reproduction in any medium, provided you give appropriate credit to the original author(s) and the source, provide a link to the Creative Commons license, and indicate if changes were made.

\section{References}

Abrams DA (1917) Effect of rate of application of loading on the compressive strength of concrete. J ASTM 17:364-377

Armaghani DJ, Mohamad ET, Hajihassani M, Yagiz S, Motaghedi H (2016a) Application of several non-linear prediction tools for estimating uniaxial compressive strength of granitic rocks and comparison of their performances. Eng Comput 32:189-206

Armaghani DJ, Mohamad ET, Momeni E, Monjezi M, Narayanasamy MS (2016b) Prediction of the strength and elasticity modulus of granite through an expert artificial neural network. Arab J Geosci 9(48):1-16

Bellair M, Pomerol L (1980) Tratado de Geolog1'a. Limusa, Mexico

Castagna JP, Batzle ML, Eastwood RL (1985) Relationships between compressional-wave and shear-wave velocities in clastic silicate rocks. Geophysics 50(4):571-581
Chelgani SC, Matin SS, Hower JC (2016a) Explaining relationships between coke quality index and coal properties by random forest method. Fuel 182:754-760

Chelgani SC, Matin SS, Makaremi S (2016b) Modeling of free swelling index based on variable importance measurements of parent coal properties by random forest method. Measurement 94:416-422

Chelgani SC, Shahbazi B, Hadavandi E (2018) Support vector regression modeling of coal flotation based on variable importance measurements by mutual information method. Measurement 114:102-108

Dehghan S, Sattari Gh, Chehreh Chelgani S (2010) Prediction of uniaxial compressive strength and modulus of elasticity for Travertine samples using regression and artificial neural networks. J Min Sci Technol 20:41-46

Demirdag S, Tufekci K, Kayacan R, Yavuz H, Altindag R (2010) Dynamic mechanical behavior of some carbonate rocks. Int J Rock Mech Min Sci 47:307-312

El Amrani Paaza N, Lamas F, Irigaray C, Chacón J (1998) Engineering geological characterisation of neogene marls in the southeastern Granada Basin, Spain. Eng Geol 50:165-175

Ersoy H, Kanik D (2012) Multicriteria decision-making analysis based methodology for predicting carbonate rocks' uniaxial compressive strength. Earth Sci Res J 16(1):65-74

Fereidooni D (2016) Determination of the geotechnical characteristics of hornfelsic rocks with a particular emphasis on the correlation between physical and mechanical properties. Rock Mech Rock Eng 49(7):2595-2608

Freund Y, Schapire RE (1996) Experiments with a new boosting algorithm. In: Thirteenth International Conference on Machine Learning-ICML, pp 148-156 
Hadavandi E, Shahrabi J, Shamshirband S (2015) A novel boostedneural network ensemble for modeling multi-target regression problems. Eng Appl Artif Intell 45:204-219

Hadavandi E, Shahrabi J, Hayashi Y (2016) SPMoE: a novel subspaceprojected mixture of experts model for multi-target regression problems. Soft Comput 20(5):2047-2065

Han M, Ren W, Liu X (2015) Joint mutual information-based input variable selection for multivariate time series modeling. Eng Appl Artif Intell 37:250-257

Hansen LK, Salamon P (1990) Neural network ensembles. IEEE Trans Pattern Anal Mach Intell 12:993-1001

Jamshidi A, Nikudel MR, Khamehchiyan M, Sahamieh RZ (2016a) The effect of specimen diameter size on uniaxial compressive strength, P-wave velocity and the correlation between them. Geomech Geoeng 11(1):13-19

Jamshidi A, Reza Nikudel M, Khamehchiyan M (2016b) A novel physico-mechanical parameter for estimating the mechanical strength of travertines after a freeze-thaw test. Bull Eng Geol Environ 76:1-10

Kerroum MA, Hammouch A, Aboutajdine D (2010) Textural feature selection by joint mutual information based on Gaussian mixture model for multispectral image classification. Pattern Recognit Lett 31:1168-1174

Lee J, Kim DW (2013) Feature selection for multi-label classification using multivariate mutual information. Pattern Recognit Lett 34(3):349-357

Malvar LJ, Ross CA (1998) Review of strain rate effects for concrete in tension. ACI Mater J 95(6):735-739

Masoudnia S, Ebrahimpour R, Arani SAAA (2012) Combining features of negative correlation learning with mixture of experts in proposed ensemble methods. Appl Soft Comput 12:3539-3551

Matin SS, Chelgani SC (2016) Estimation of coal gross calorific value based on various analyses by random forest. Fuel 177:274-278

Matin SS, Hower JC, Chelgani SC (2016) Explaining relationships among various coal analyses with coal grindability index by random forest. Int J Miner Process 155:140-146
Matin SS, Farahzadi L, Makaremi S, Chelgani SC, Sattari Gh (2017) Variable selection and prediction of uniaxial compressive strength and modulus of elasticity by Random Forest. Appl Soft Comput 70:980-987 (in press)

Pickett GR (1963) Acoustic character logs and their applications in formation evaluation. J Petrol Technol 15(6):659-667

Shahbazi B, Chelgani SC, Matin SS (2017) Prediction of froth flotation responses based on various conditioning parameters by random forest method. Coll Surf A Physicochem Eng Asp 529:936-941

Solomatine DP, Shrestha DL (2004) AdaBoost. RT: a boosting algorithm for regression problems. In: Neural networks, 2004. Proceedings. 2004 IEEE International Joint Conference, pp $1163-1168$

Sousa LMO (2014) Petrophysical properties and durability of granites employed as building stone: a comprehensive evaluation. Bull Eng Geol Environ 73:569-588

Tian J, Li M, Chen F, Kou J (2012) Coevolutionary learning of neural network ensemble for complex classification tasks. Pattern Recogn 45:1373-1385

Watstein D (1953) Effect of straining rate on the compressive strength and elastic properties of concrete. ACI Mater J 49:729-744

Yan DM, Lin G (2006) Dynamic properties of plain concrete in direct tension. Cem Concr Res 36:1371-1378

Yasar E, Erdogan Y (2004a) Correlating sound velocity with the density, compressive strength and Young's modulus of carbonate rocks. Int J Rock Mech Min Sci 41:871-875

Yasar E, Erdogan Y (2004b) Estimation of rock physicomechanical properties using hardness methods. Eng Geol 71:281-288

Zhai J, Xu H, Wang X (2012) Dynamic ensemble extreme learning machine based on sample entropy. Soft Comput 16:1493-1502

Publisher's Note Springer Nature remains neutral with regard to jurisdictional claims in published maps and institutional affiliations. 